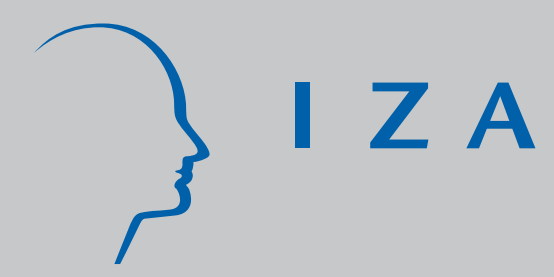

IZA DP No. 3865

A Nonparametric Examination of Capital-Skill Complementarity

Daniel J . Henderson

November 2008 


\title{
A Nonparametric Examination of Capital-Skill Complementarity
}

\author{
Daniel J. Henderson \\ State University of New York at Binghamton \\ and IZA
}

Discussion Paper No. 3865

November 2008

\author{
IZA \\ P.O. Box 7240 \\ 53072 Bonn \\ Germany \\ Phone: +49-228-3894-0 \\ Fax: +49-228-3894-180 \\ E-mail: iza@iza.org
}

Any opinions expressed here are those of the author(s) and not those of IZA. Research published in this series may include views on policy, but the institute itself takes no institutional policy positions.

The Institute for the Study of Labor (IZA) in Bonn is a local and virtual international research center and a place of communication between science, politics and business. IZA is an independent nonprofit organization supported by Deutsche Post World Net. The center is associated with the University of Bonn and offers a stimulating research environment through its international network, workshops and conferences, data service, project support, research visits and doctoral program. IZA engages in (i) original and internationally competitive research in all fields of labor economics, (ii) development of policy concepts, and (iii) dissemination of research results and concepts to the interested public.

IZA Discussion Papers often represent preliminary work and are circulated to encourage discussion. Citation of such a paper should account for its provisional character. A revised version may be available directly from the author. 
IZA Discussion Paper No. 3865

November 2008

\section{ABSTRACT}

\section{A Nonparametric Examination of Capital-Skill Complementarity ${ }^{*}$}

This paper uses nonparametric kernel methods to construct observation-specific elasticities of substitution for a balanced panel of 73 developed and developing countries to examine the capital-skill complementarity hypothesis. The exercise shows some support for capital-skill complementarity, but the strength of the evidence depends upon the definition of skilled labor and the elasticity of substitution measure being used. The added flexibility of the nonparametric procedure is also able to uncover that the elasticities of substitution vary across countries, groups of countries and time periods.

JEL Classification: $\quad \mathrm{C} 14, \mathrm{C} 23, \mathrm{D} 2$

Keywords: capital-skill complementarity, elasticity of substitution, nonparametric kernel, stochastic dominance

Corresponding author:

Daniel J. Henderson

Department of Economics

State University of New York at Binghamton

Binghamton, NY 13902-6000

USA

E-mail: djhender@binghamton.edu

\footnotetext{
* The author wishes to thank two anonymous referees, the editor Jonathan Temple, Viera Chemlarova, David Drukker, John Duffy, Li Gan, Subal Kumbhakar, Qi Li, Daniel Millimet, Salvatore Modica, Chris Papageorgiou, Chris Parmeter, Fidel Perez-Sebastian, Jeff Racine and Robert Russell for suggestions which led to an improved version of this paper. Comments from participants in the Texas A\&M University Econometrics Seminar Series, the Sam Houston State University Department Seminar Series, the University of Houston/Rice University Macroeconomics Seminar Series, the Fifteenth Annual Meeting of the Midwestern Econometrics Group (Carbondale, IL) and the Institutional and Social Dynamics of Growth and Distribution Conference (Lucca, Italy) are also greatly appreciated. Finally, the author would like to thank Ozkan Eren and Ayfer Gurun for excellent research assistance.
} 


\section{Introduction}

Rising wage inequality has been a key feature of the U.S. labor market since the late 1970s. This phenomenon, both in the United States and worldwide, has received much attention in the literature. One possible explanation is provided by the capital-skill complementarity (CSC) hypothesis. The hypothesis states that physical capital and skilled labor are more complementary than unskilled labor and physical capital. Assuming the hypothesis is true, an increase in physical capital, ceteris paribus, will increase the demand for skilled labor (and thus wages for skilled laborers). Capital-deepening seen across many economies in recent years combined with CSC could be one such explanation for rising wage inequality. Thus, if significant increases in physical capital have been made and CSC is shown to hold for a particular economy, policymakers could use this information to possibly find ways to decrease inequality.

Griliches (1969) finds empirical evidence that physical capital and skilled labor are less substitutable than physical capital and unskilled labor and concludes that the CSC hypothesis holds using a data set of U.S. manufacturers. Since Griliches (1969), the CSC hypothesis has been empirically studied in great detail. While some authors debate the specification of the model, others debate the type of data which should be studied. Fallon and Layard (1975), and others, study the CSC hypothesis on an international scale. Specifically, they piece together data from 22 developed and developing countries for the year 1963. They find mild evidence in favor of the CSC hypothesis. Duffy, Papageorgiou, and Perez-Sebastian (2004), hereafter DPP, extend the work of Fallon and Layard (1975) to a balanced data set of 73 countries over a 25 year period (1965-90). They use a two-level constant elasticity of substitution production function specification and use nonlinear estimation methods which allow them to relax the assumption of perfectly competitive markets. Further, they present five alternative ways of dividing the labor force into two categories, 'skilled' and 'unskilled'. ${ }^{1}$ This allows them to find the greatest support for CSC when the category for skilled laborers

\footnotetext{
${ }^{1}$ These categories or thresholds will be described in greater detail in Section 3.
} 
is defined as those who have attained some secondary education, those who have completed primary education or as those who gained some primary education. Part of their purpose for looking at an international panel was to find evidence of CSC over long periods of time and across countries at different stages of development. This strategy was partly influenced by Goldin and Katz (1998) who note that physical capital and skilled labor have not always been viewed as relative complements. In particular, they suggest that transitions between production processes change the relative demand for skill, thus different economies at different times may or may not possess CSC.

Most studies simply give a single conclusion for all observations. This could prove to be detrimental. For example, suppose a researcher found that CSC exists in a panel of countries. Then if countries take that information as given, it may affect their policy. If CSC holds true for that economy, it could increase spending on education to potentially reduce the impact of advancing technology on inequality. However, if CSC does not exist, those resources spent on education may have been better allocated.

Although observation-specific estimates seem logical, the aforementioned papers simply give a single estimate for each elasticity. ${ }^{2}$ An increasingly popular method to obtain observation-specific estimates is to use nonparametric kernel methods. In addition, these methods have the luxury of not having to assume a specific functional form for the technology. This technique is extremely beneficial here because as DPP (pp. 331) note, 'there is no consensus yet on the appropriate functional form to use to capture capital-skill complementarity.' Thus, if one chooses a specific functional form, and that assumption is incorrect, estimation will likely lead to inconsistent parameter estimates.

This paper uses nonparametric methods to study the CSC hypothesis. The approach allows for at least three contributions to the literature. (1) The nonparametric technique allows the model to be solved using a single-level production function. (2) It decreases

\footnotetext{
${ }^{2}$ There is, however, some work being done with translog cost functions (which require price data) that allow for observation-specific estimates (Bergström and Panas, 1992; Ruiz-Arranz, 2002).
} 
the number of assumptions of the model, including the choice of functional form for the technology and (3) it allows for observation-specific estimates of elasticities of substitution.

The main finding of the paper shows some support for the CSC hypothesis. As in DPP, the elasticities of substitution between physical capital and skilled labor are generally smaller than the elasticities of substitution between physical capital and unskilled labor, but the difference is often insignificant. Stochastic dominance (SD) tests show some support

for CSC, but the evidence depends upon the measure used and the definition of a skilled laborer. Subsequent analysis breaks down the elasticities across pre-specified groups. As hypothesized by Goldin and Katz (1998), it is shown that the degree of substitutability varies amongst countries, across groups of countries and across time.

The remainder of the paper is organized as follows: Section 2 describes the model, gives a brief history of elasticity of substitution measures, and describes the estimation procedure as well as the SD testing procedure. The third section gives the data while the fourth describes the results. Finally, the fifth section concludes.

\section{Methodology}

\section{Model}

Consider the simple aggregate production model of the form

$$
Y=f(K, S, N)
$$

where the function $f$ transforms inputs into aggregate output $(Y) . K$ represents the capital stock, and $S$ and $N$ represent skilled and unskilled labor, respectively. The CSC hypothesis states that capital and skilled labor are more complementary than capital and unskilled labor. Formally, denoting $\sigma_{q l}$ as the elasticity of substitution between inputs $q$ and $l$, CSC is 
said to hold if $\sigma_{K S}<\sigma_{K N}$. That is, $K$ and $S$ are less substitutable (or more complementary) than $K$ and $N$.

\section{Elasticity of Substitution Measures}

The elasticity of substitution measure, first developed by Hicks (1932), measures the percentage change in factor proportions due to a change in the marginal rate of technical substitution

in a two-input world. It is, effectively, a measure of the curvature of an isoquant. Although this result is intuitive, complication occurs when one allows for more than two inputs. Several measures have since been created in order to combat this complication. Unfortunately, there is no consensus on the appropriate measure for the elastity of substitution between inputs $q$ and $l$ for the multiple-input production function $y=f\left(x_{1}, x_{2}, \ldots, x_{P}\right)$.

One such measure, which has fallen out of fashion in the literature, is the direct elasticity of substitution (DES) defined by Allen and Hicks (1934). The measure, which defines the elasticity of substitution between inputs $x_{q}$ and $x_{l}$ as

$$
\sigma_{q l}^{D}=\frac{x_{q} f_{q}+x_{l} f_{l}}{x_{q} x_{l}} \frac{H_{q l}}{|H|},
$$

where

$$
H=\left[\begin{array}{cccc}
0 & f_{1} & \cdots & f_{P} \\
f_{1} & f_{11} & \cdots & f_{1 P} \\
\vdots & \vdots & \ddots & \vdots \\
f_{P} & f_{P 1} & \cdots & f_{P P}
\end{array}\right]
$$

$|H|$ is the determinant of the bordered Hessian, $H_{q l}$ is the cofactor of the element $f_{q l}$ in $H$, and $f_{q}, f_{q q}$, and $f_{q l}$ represent the first partial, second partial, and cross-partial derivatives of the production function respectively, can be interpreted as $\partial \log \left(x_{q} / x_{l}\right) / \partial \log \left(f_{l} / f_{q}\right)$ for constant output and other input quantities. The downfall of this measure is that it is identical to the two-input case, effectively assuming that the other factors in the production function 
are fixed and can be ignored. In fact, it is only theoretically plausible to use this aggregate production function if all factors are being competitively allocated. If one factor is being held constant, then an aggregate production function no longer exists.

The most popular measure in the literature is the Allen-Uzawa (or the partial) elasticity of substitution (AES). This method, first suggested by Allen and Hicks (1934) and further studied by Allen (1938) and Uzawa (1962), has become a staple in the applied literature. It was designed to combat the downfall of the DES measure (by attempting to examine changes in other inputs) and is formally defined as

$$
\sigma_{q l}^{A}=\frac{\sum_{p=1}^{P} x_{p} f_{p}}{x_{q} x_{l}} \frac{H_{q l}}{|H|},
$$

where $x_{p}$ is the $p$ th input and $f_{p}$ is the $p$ th first partial derivative of the production function, $p=1,2, \ldots P$. Although the measure is continually used, it has met sharp criticism. Blackorby and Russell (1989) show that the Allen-Uzawa measure fails to preserve the relevant properties of the original Hicksian notion (for the multi-input case). They further state (pp. 883) that 'as a quantitative measure, it has no meaning; as a qualitative measure, it adds no information to that contained in the (constant output) cross-price elasticity. In short, the AES is (incrementally) completely uninformative.' Perhaps the only redeeming feature of the AES is that it preserves the sign of the compensated derivative.

In its place they suggest an alternative elasticity of substitution measure originally published in Japanese by Morishima (1967) and independently discovered by Blackorby and Russell (1975, 1981). This measure, which Klump and de La Grandville (2000) term the Morishima-Blackorby-Russell elasticity of substitution (MES), preserves the salient characteristics of the original Hicksian concept, which are lacking in the Allen-Uzawa measure. ${ }^{3}$ This measure is usually employed when estimating cost functions (Thompson and Taylor,

\footnotetext{
${ }^{3}$ The under-cited Klump and de La Grandville (2000) paper not only suggests the name for the elasticity of substitution measure, it also proposes that empirical growth research in this area be based on the MES.
} 
1995), but is also used when estimating production functions (Hoff, 2004) and has a wellknown relationship to the partial elasticity of substitution:

$$
\begin{aligned}
\sigma_{q l}^{M} & =\frac{f_{l}}{x_{q}} \frac{H_{q l}}{|H|}-\frac{f_{l}}{x_{l}} \frac{H_{q l}}{|H|} \\
& =\frac{f_{l} x_{l}}{f_{q} x_{q}}\left(\sigma_{q l}^{A}-\sigma_{l l}^{A}\right)
\end{aligned}
$$

A detailed examination of this formula shows two important facts. First, a pair of goods can be complements in terms of the AES, but substitutes according to the MES. On the other hand, if two goods are substitutes according to the AES, they are always substitutes according to the MES. Thus, either the MES has a bias towards treating inputs as substitutes or the AES has a bias towards treating them as complements. Second, the MES is asymmetric. Although some view this as an unusual property, Blackorby and Russell $(1981,1989)$ argue that this should be natural for the multi-input case.

When examining the asymmetric property for this data set, it is found that, in general, the absolute value of $\sigma_{K S}$ is less than $\sigma_{S K}$ and at the same time $\sigma_{K N}$ is less than $\sigma_{N K}$. What these inequalities (literally) say is that the capital-labor ratio (skilled or unskilled) is more sensitive to changes in the marginal product of capital than to changes in the marginal product of labor. Given that the main conclusions of the paper do not change with either measure, to conserve space, the paper chooses to focus on the estimates of $\sigma_{K S}$ and $\sigma_{K N}$. The results using $\sigma_{S K}$ and $\sigma_{N K}$ are available in Appendix A. ${ }^{4}$ For a more detailed discussion on elasticity of substitution measures see Allen (1938), Allen and Hicks (1934), Blackorby and Russell (1975; 1981; 1989), Chambers (1988), Hicks (1932; 1946), and McFadden (1963).

\section{Nonparametric Estimation of Production Functions}

Nonparametric estimation of production functions is not new, but the literature is somewhat scattered. The term nonparametric estimation encompasses a broad range of procedures.

\footnotetext{
${ }^{4}$ All appendicies for the paper are available at http://bingweb.binghamton.edu/ djhender/pdffiles/h obes appendix.pdf.
} 
Early attempts to estimate production functions using kernel methods can be found in, for example, Vinod and Ullah (1988) and Kneip and Simar (1996). Other methods to estimate production functions include Allon et al. (2007) who use entropy measures, Chavas and Cox (1988) who use Data Envelopment Analysis, Epple et al. (2007) who use series estimation, Kumbhakar et al. (2007) who use local-maximum likelihood estimation and Lewbel and Linton (2007) who use nonparametric matching estimators.

The choice of which methodology to choose depends on the problem at hand and the data in question. This paper uses Li-Racine Generalized Kernel Estimation (Li and Racine, 2004; Racine and Li, 2004). This methodology is not new to the estimation of production functions. For example, Henderson and Kumbhakar (2006) use generalized kernel estimation to estimate the U.S. aggregate production function and examine the public capital productivity puzzle. The benefit of this procedure is that it smooths both continuous and categorical regressors. Besides the obvious benefit of not having to automatically resort to a semiparametric procedure, the rate of convergence of the estimators depend only on the number of continuous regressors. In other words, adding additional categorical regressors does not accelerate the curse of dimensionality. This is especially important because the data set being studied is relatively small.

\section{Generalized Kernel Estimation}

Here, generalized kernel estimation is used to estimate the (single level) production function (1), which may be written as

$$
Y_{i}=m\left(x_{i}\right)+u_{i}, \quad i=1,2, \ldots, N T
$$

$Y$ is the output variable measured in levels, $m(\cdot)$ is the unknown smooth production function with argument $x_{i}=\left(x_{i}^{c}, x_{i}^{u}, x_{i}^{o}\right), x_{i}^{c}=\left(K_{i}, S_{i}, N_{i}\right)$ is a vector of continuous inputs measured

in levels, $x_{i}^{u}$ is a vector of regressors that assume unordered discrete values (in this case a single variable for geographic region), $x_{i}^{o}$ is a vector of regressors that assume ordered discrete 
values (in this case a single variable for time), $u$ is the additive error, $N$ is the number of countries, and $T$ is the number of time periods $(N=73, T=6) .{ }^{5}$ Taking a second-order Taylor expansion of (5) with respect to $x_{j}$ yields

$$
Y_{i} \approx m\left(x_{j}\right)+\left(x_{i}^{c}-x_{j}^{c}\right) \beta\left(x_{j}\right)+0.5\left(x_{i}^{c}-x_{j}^{c}\right)^{\prime}\left(x_{i}^{c}-x_{j}^{c}\right) \gamma\left(x_{j}\right)+u_{i},
$$

where $\beta(x)(\equiv \nabla m(x))$ is the partial derivative of $m(x)$ with respect to $x^{c}$ and $\gamma(x)(\equiv$ $\left.\nabla_{2} m(x)\right)$ is the Hessian.

The local-quadratic least-squares estimator of $\delta(x) \equiv(m(x), \beta(x), \gamma(x))^{\prime}$ is given by

$$
\widehat{\delta}(x)=(\widehat{m}(x), \widehat{\beta}(x), \widehat{\gamma}(x))^{\prime}=\left(X^{\prime} K(x) K\right)^{-1} X^{\prime} K(x) Y,
$$

where $X=\left(1,\left(x_{i}^{c}-x_{j}^{c}\right),\left(x_{i}^{c}-x_{j}^{c}\right)^{\prime}\left(x_{i}^{c}-x_{j}^{c}\right)\right)$ and $K(x)$ is a $N T \times N T$ diagonal matrix of kernel (weight) functions commonly used for mixed data (Hall et al., 2007; Li and Racine, 2006). ${ }^{6}$

\section{Bandwidth Selection}

Estimation of the bandwidths is typically the most salient factor when performing nonparametric estimation. Although there exist many selection methods, this study utilizes Hurvich et al.'s (1998) Expected Kullback Leibler $\left(A I C_{c}\right)$ criteria. This method - which chooses smoothing parameters using an improved version of a criterion based on the Akaike

\footnotetext{
${ }^{5}$ Maasoumi, Racine and Stengos (2007) use generalized kernel estimation in their study of a nonparametric growth regression and include OECD status as a categorical regressor. They do this to control for differences between groups of countries similar to the way a dummy variable shifts the intercept in a linear model. However, with Generalized Kernel Estimation the categorical variable is allowed to interact with the other regressors in an unknown fashion. Following the lead of Temple (1998), in addition to OECD status, the regional categorical variable includes categories for Africa, the Caribbean, Latin American, the Middle East, and Asia. The results of the exercise were also examined solely using OECD status and although these coefficients have more variation, the main conclusions of the paper do not change. The results are available upon request.

${ }^{6}$ It should be noted that the second-order Taylor expansion and thus estimation of the model by localquadratic least-squares is not necessary here. For instance, estimation of (5) can be performed using localconstant least-squares (which estimates only the unknown function) and then separately obtaining the derivatives of $m(\cdot)$ (Pagan and Ullah, 1999; Rilstone and Ullah, 1989; Ullah, 1988a,b). For further information on the benefits and relationships between local constant, linear and quadratic least-squares, see Fan and Gijbels (1996).
} 
Information Criterion - has been shown to perform well in small samples and avoids the tendency to undersmooth as often happens under other approaches such as Least-Squares Cross-Validation. Specifically, the bandwidths are chosen to minimize

$$
A I C_{c}=\log \left(\widehat{\sigma}^{2}\right)+\frac{1+\operatorname{tr}(H) / N T}{1-[\operatorname{tr}(H)+2] / N T}
$$

where

$$
\begin{aligned}
\widehat{\sigma}^{2} & =\frac{1}{N T} \sum_{j=1}^{N T}\left(Y_{j}-\widehat{m}\left(x_{j}\right)\right)^{2} \\
& =\left(\frac{1}{N T}\right) Y^{\prime}(I-H)^{\prime}(I-H) Y
\end{aligned}
$$

and $\widehat{m}\left(x_{j}\right)=H Y_{j}$.

A major benefit of nonparametric type estimators is that they give a separate estimate for each observation. This allows one to construct observation-specific estimates of (2), (3), and (4), where observation-specific values of $f_{q}=\frac{\partial m(\cdot)}{\partial x_{q}}, f_{q q}=\frac{\partial^{2} m(\cdot)}{\partial x_{q}^{2}}$, and $f_{q l}=\frac{\partial^{2} m(\cdot)}{\partial x_{q} \partial x_{l}}$ are retrieved from $\widehat{\beta}(x)$ and $\widehat{\gamma}(x)$. This result allows one to track elasticity of substitution estimates across countries and over time.

The nonparametric model gives several other important benefits over the parametric models. ${ }^{7}$ First, the model does not require the elasticity of substitution between $N$ and $S$ to be the same as that between $K$ and $N$ (equation 1 in DPP) or $K$ and $S$ (equation 2 in DPP). ${ }^{8}$ Second, the model does not require Hicks-neutral technological growth (equations 5

\footnotetext{
${ }^{7}$ It should also be noted here that the translog model allows for observation-specific estimates and a partial relaxation of the functional form. However, there are a few downfalls to the second-order Taylor approximation of the constant elasticity of substitution production function. First, as compared to the nonparametric model, it is more restrictive. Second, some authors have found that the translog model sometimes gives poor results (Kmenta, 1967; Thursby and Lovell, 1978). Results for this paper were also estimated using the translog production function. It was found that these results were less intuitive than the nonparametric model, but are available from the author upon request.

${ }^{8}$ In the estimation of the model it is found that the elasticities of substitution between $N$ and $S$, and $K$ and $N$ or $K$ and $S$ are not equal. The results for elasticities of subsitution between $N$ and $S$ are not reported in the tables, but are available from the author upon request.
} 
and 6 in DPP). Finally, it allows for time effects which are allowed to vary across countries (embodied technical change).

\section{Identification}

In theory, the relationship between capital-skill complementarity and the distribution of income relies on a number of assumptions. Some of them are general to much of the production theory literature such as returns to scale. Some are special to the capital-skill complementarity literature. With nonparametric estimation it is not entirely clear to what extent the elasticities obtained are able to confirm or refute theoretical predictions.

Perhaps more important than refuting/confirming theories is the issue of identification. Diamond et al. (1978) show for what conditions the elasticities of substitution and patterns of technological change can be identified and for what conditions they cannot be identified. For example, the Cobb-Douglas production function implicitly assumes that the elasticity of substitution between inputs is equal to one. Hence, simultaneous nonparametric identification is not guaranteed because the nonparametric model nests the Cobb-Douglas model. In that sense, the nonparametric model is not fully identified.

Given that the nonparametric model is not fully identified if the true underlying data generating process is one in which we cannot identify each of the parameters, we could potentially estimate the nonparametric model and then test whether or not it is different from those known 'problematic' parametric functional forms. For example, using the Hsiao et al. (2007) test for correct parametric functional form, the Cobb-Douglas model is rejected at the $1 \%$ level for each data set run in this paper. However, this approach, of course, is infeasible in practice. A likely better solution would be to develop tests for the conditions outlined in Diamond et al. (1978). If it is found that the conditions do not hold, then procedures may be developed to estimate the nonparametric model imposing these assumptions (for example, neutral technological change). There is a small literature on testing for structure (Bowman et al., 1998; Hall and Van Keilgom, 2005) and imposing structure in nonparametric kernel 
estimators (Hall and Huang, 2001; Hall et al., 2002). This possibility suggests a non-trivial future research agenda.

\section{Stochastic Dominance}

Nonparametric estimation as described in equation (7) allows one to generate unique elasticity of substitution estimates for each observation. To examine the empirical comparisons between elasticities, this paper uses a SD approach. The comparison of the elasticities of substitution between physical capital, and skilled and unskilled labor on a particular index is highly subjective; different indices may yield different substantive conclusions. In contrast, finding a SD relation provides uniform ranking regarding the elasticities of substitution and offers robust inference.

To proceed, let $\sigma_{K N_{i}}$ be the actual elasticity of substitution between physical capital and unskilled labor unique to an individual country during a specific year. $\sigma_{K S_{i}}$ is defined similarly. In practice, the actual elasticities of substitution are unknown, but the nonparametric regression allows us to construct an estimate of each of these. Define $\left\{\widehat{\sigma}_{K N}\right\}_{i=1}^{N T}$ as a vector of $N T$ estimates of $\sigma_{K N}$ and $\left\{\widehat{\sigma}_{K S}\right\}_{i=1}^{N T}$ as an analogous vector of estimates of $\sigma_{K S}$. Let $G\left(\sigma_{K N}\right)$ and $F\left(\sigma_{K S}\right)$ represent the cumulative distribution functions of $\sigma_{K N}$ and $\sigma_{K S}$, respectively.

Consider the null hypotheses of interest as Equality of Distributions :

$$
G\left(\sigma_{K N}\right)=F\left(\sigma_{K S}\right) \quad \forall \sigma_{K N} \cup \sigma_{K S} \in \Omega
$$

First Order Stochastic Dominance : $G$ dominates $F$ (CSC) if

$$
G\left(\sigma_{K N}\right) \leq F\left(\sigma_{K S}\right) \quad \forall \sigma_{K N} \cup \sigma_{K S} \in \Omega,
$$


where $\Omega$ is the union support for $\sigma_{K N}$ and $\sigma_{K S}$. To test this null hypothesis, define the empirical cumulative distribution function for $\sigma_{K N}$ as

$$
\widehat{G}\left(\sigma_{K N}\right)=\frac{1}{N T} \sum_{i=1}^{N T} 1\left(\widehat{\sigma}_{K N} \leq \sigma_{K N}\right)
$$

where $1(\cdot)$ denotes the indicator function and $\widehat{F}\left(\sigma_{K S}\right)$ is defined similarly. Next, define the following Kolmogorov-Smirnov statistics

$$
\begin{gathered}
T_{E Q}=\sup _{\sigma_{K N} \cup \sigma_{K S} \in \Omega}\left|\widehat{G}\left(\sigma_{K N}\right)-\widehat{F}\left(\sigma_{K S}\right)\right| ; \\
T_{F S D}=\sup _{\sigma_{K N} \cup \sigma_{K S} \in \Omega}\left\{\widehat{G}\left(\sigma_{K N}\right)-\widehat{F}\left(\sigma_{K S}\right)\right\} ;
\end{gathered}
$$

for testing the equality and first order stochastic dominance (FSD) relation, respectively.

Unfortunately, the asymptotic distributions of these nonparametric sample-based statistics under the null are generally unknown because they depend on the underlying distributions of the data. Thus one needs to approximate the empirical distributions of these test statistics to overcome this problem. The strategy following Abadie (2002) is as follows:

(i) Let $T$ be a generic notation for $T_{E Q}$ and for $T_{F S D}$. Compute the test statistics $T$ for the original sample of $\left\{\widehat{\sigma}_{K N_{1}}, \widehat{\sigma}_{K N_{2}}, \ldots, \widehat{\sigma}_{K N_{N T}}\right\}$ and $\left\{\widehat{\sigma}_{K S_{1}}, \widehat{\sigma}_{K S_{2}}, \ldots, \widehat{\sigma}_{K S_{N T}}\right\}$. (ii) Define the pooled sample as $\Omega=\left\{\widehat{\sigma}_{K N_{1}}, \widehat{\sigma}_{K N_{2}}, \ldots, \widehat{\sigma}_{K N_{N T}}, \widehat{\sigma}_{K S_{1}}\right.$, $\left.\widehat{\sigma}_{K S_{2}}, \ldots, \widehat{\sigma}_{K S_{N T}}\right\}$. Resample $N T+N T$ observations with replacement from $\Omega$ and call it $\Omega_{b}$. Divide $\Omega_{b}$ into two groups to obtain $\widehat{T}_{b}$.

(iii) Repeat step (ii) $B$ times.

(iv) Calculate the p-value of the test with p-value $=B^{-1} \sum_{b=1}^{B} 1\left(\widehat{T}_{b}>T\right)$. Reject the null hypotheses if the p-value is smaller than some significance level $\alpha$, where $\alpha \in(0,1 / 2)$ 
By resampling from $\Omega$, we approximate the distribution of the test statistics when $G\left(\sigma_{K N}\right)=F\left(\sigma_{K S}\right)$. Note that for $(12 \mathrm{~b}), G\left(\sigma_{K N}\right)=F\left(\sigma_{K S}\right)$ represents the least favorable case for the null hypothesis. This strategy allows us to estimate the supremum of the probability of rejection under the composite null hypothesis, which is the conventional definition of test size. ${ }^{9}$

\section{Data}

The data used in this paper are identical to that of DPP and will only be briefly described here. Real GDP $(Y)$ and investment shares $(I)$ as well as labor $(L)$ are obtained from the Penn World Tables, Mark 5.6. The physical capital stock $(K)$ data are constructed by using the investment shares data and the perpetual inventory method. Real GDP and physical capital are both measured in constant U.S. dollars (1985 international prices).

Given the limited availability of educational data, there are six annual observations for each of the 73 countries (both developed and developing), spaced 5 years apart, over the period 1965-90. Five proxies are constructed for skilled and unskilled labor (because it is unclear how skilled labor should be defined in a cross-country analysis) based on the Barro and Lee (2001) international education data set. In the Barro and Lee (2001) data set observations are available once every five years. This helps explain the nature of the sample. Formally, DPP obtain each of the skilled labor variables $(S)$ by multiplying achievement rates for a particular cutoff criterion by the size of the labor force in each country at each point in time as $S=e \times L$. Here, $e$ is the percentage of the adult population in a particular country in a particular year who have a given level of education and $L$ is the labor force for that same observation. Unskilled labor $(N)$ is defined similarly as $N=(1-e) \times L$.

\footnotetext{
${ }^{9}$ Ideally one would like to reestimate the nonparametric returns within each bootstrap replication to take into account the uncertainty of the returns. Unfortunately, it could be argued that in doing this one should reestimate the bandwidths for each bootstrap replication, which would be extremely computationally difficult, if not impossible. Thus, the bootstrapped p-values most likely differ slightly from their 'true' values. Nonetheless, if one obtains a large p-value, it is unlikely that accounting for such uncertainty would alter the inference. Determining an ideal bootstrapping procedure is left for future research.
} 
For a given cutoff criterion, the proxies for skilled labor are as follows: $(S 1)$ workers who have attained some college, $(S 2)$ workers who have completed secondary education, $(S 3)$ workers who have attained some secondary education, $(S 4)$ workers who have completed primary education, and (S5) workers who have attained some primary education. The remaining portion of the labor force in each category is considered unskilled labor, and is correspondingly labeled as $N 1, N 2, N 3, N 4$, and $N 5$, respectively. It should be obvious that $S 1 \leq S 2 \leq S 3 \leq S 4 \leq S 5$ and that $N 1 \geq N 2 \geq N 3 \geq N 4 \geq N 5$. Further, given that a certain percentage of the labor force is deemed skilled and the remainder unskilled, the sum of skilled and unskilled must equal the labor force. In other words, $S 1+N 1=S 2+N 2=$ $S 3+N 3=S 4+N 4=S 5+N 5=L$.

\section{Results}

Before diving into tables and formal statistical tests, one can innocently look at the percentage of elasticities between skilled labor and physical capital which are smaller than their corresponding elasticities between unskilled labor and physical capital. Performing this naive operation shows that, in all but one circumstance, a majority of the observations have elasticities of substitution between physical capital and skilled labor which are less than their corresponding elasticities of substitution between physical capital and unskilled labor. The lone outlier is when skilled labor is defined as attained some secondary education and when using the DES measure. That being said, this percentage is 0.411 . The other thresholds for the DES measure range from 0.541 to 0.739 . At the same time, the percentages range from 0.515 to 0.689 for the AES and from 0.562 to 0.650 for the Morishima-Blackorby-Russell measure. This shows that regardless of how a skilled laborer is defined, a majority of the observations show evidence of CSC. Although this type of approach is informative, it lacks any consideration of sampling variability. 
The main results of this study are displayed in Tables 1-4. Table 1 gives the SD tests for the equality of distributions of elasticities, as well as tests for FSD. Table 2 presents a summary of the elasticities of substitution between physical capital, and skilled and unskilled labor. The table reports the elasticity of substitution at the 25 th, 50 th and 75 th percentile (labelled Quartile 1, 2 and 3) along with the corresponding standard error below each estimate in italics. Table 3 presents the median results for specific groups of countries across the sample and Table 4 gives the median elasticities for each time period. For the sake of comparison, the first table gives the results for each elasticity of substitution measure. For the sake of brevity, as well as following the suggestion of Klump and de La Grandville (2000), the final three tables give the results for only the MES. ${ }^{10}$

\section{Stochastic Dominance Tests}

To formally test the differences between the estimated distributions of parameter estimates, SD tests are employed. Here two separate null hypotheses are tested First, the null that the distribution (for all countries over all time periods) of the estimated elasticity of substitution between physical capital and skilled labor (at a given threshold) is different from the distribution of the estimated elasticity of substitution between physical capital and unskilled labor (at the same threshold) is tested. Once it has been determined that the distributions are different from one another, the test for the null that $\sigma_{K N}$ first order dominates $\sigma_{K S}$ is performed. This test will provide statistical evidence of whether or not there exists a first order dominance relation, and hence, if there is evidence of CSC across the entire sample for a given definition of skilled labor.

The results of the tests are reported in Table 1 . In each circumstance, the tests reject the null that the two distributions are equal at conventional confidence levels. These results differ across thresholds and across elasticity of substitution measures. Among the various elasticity of substitution choices, there is some significant evidence of CSC at each threshold.

\footnotetext{
${ }^{10}$ The results of the three tables for the other elasticity of substitution measures are available in Appendix B.
} 
In the fifteen (five thresholds $\times$ three measures) cases considered, failure to reject the null of CSC (p-values in excess of 0.500 ) obtains in seven of them. ${ }^{11}$

Although at each threshold there is some evidence of CSC, the results for significance differ according to the elasticity of substitution measure. For the DES measure, there appears to be strong evidence of CSC for the lower two thresholds and no evidence for the higher three thresholds. The AES only shows significant evidence of CSC for the second and third thresholds and the MES measure only shows significant evidence for the highest three thresholds.

In sum, employing SD tests on the elasticity of substitution estimates reveals at least two findings. First, SD tests find some support for CSC in each of the thresholds. Second, the SD tests reveal that the evidence is not uniform across elasticity of substitution measures or definitions of skilled labor. There are cases where the cumulative distributions cross and in these cases we cannot conclude CSC across the sample.

\section{Comparison of Quartiles}

Given that we do not find FSD at each threshold for a given measure, it may prove fruitful to examine the quartiles of the elasticity of substitution estimates. Table 2 gives the individual elasticity of substitution estimates at their quartiles for each of the definitions of skilled labor. When using nonlinear least squares (with or without fixed effects) DPP find general evidence for CSC. Further, they find stronger evidence when skilled labor is defined as those who have attained some secondary education, completed primary education or attained some primary education and insignificant evidence when skilled labor is defined as workers who have attained some college or workers who have completed secondary education. However, when using a GMM-IV estimator, their evidence for CSC is greatly weakened.

The former method is comparable to the nonparametric approach in this paper. Table 2 shows that for each threshold, the results show an overwhelming majority (14 of the 15) of the

\footnotetext{
${ }^{11}$ Here the upper bound of 0.500 is chosen as the critical point for testing the null hypotheses given the sample size and concerns of uncertainty in the elasticities.
} 
quartiles show evidence of CSC. Unfortunately, a majority of this evidence is insignificant. In fact of those 14 quartiles that show evidence of CSC, only three of them show significant evidence of CSC. This finding can be consistent with at least two stories. First, it may be an artifact of the small sample. Second, it may be difficult to obtain a significant result because, as Goldin and Katz (1998) argue, CSC is subject to change and may or may not hold for different countries in different time periods.

If the study were to stop here, it would conclude with DPP (pp. 340) that 'there is some evidence in support of the capital-skill complementarity hypothesis at the aggregate production level, but the evidence is not very strong.' Fortunately, the nonparametric approach allows for observation-specific estimates and thus the estimates can be further broken down to examine different strata.

\section{Comparison by Group}

Although results at the quartiles are informative, one can always wonder how groups of countries behave together. Table 3 reports the median elasticity of substitution for specific groups of countries. ${ }^{12}$ The table shows CSC for most groups at most thresholds. A few points are worth noting. First, for each of the groups, CSC generally holds for the median values. This should not necessarily be surprising. These results are consistent with those in the second quartile of Table 2. Second, the median elasticity of substitution between physical capital and skilled labor for the OECD countries is generally less than that of the non-OECD countries, but greater than that of the Latin American countries. Second, the elasticity of substitution between physical capital and unskilled labor is the smallest for OECD countries, regardless of the threshold. However, more important is the prevalence of CSC across groups. Here it is seen that CSC is more pronounced in non-OECD economies as opposed to OECD economies. The same holds true for Latin American countries as compared to OECD countries.

\footnotetext{
${ }^{12}$ The median refers to the median elasticity of substitution for all countries in a specific group over all periods studied.
} 
These result are not necessarily surprising. In a recent paper, Papageorgiou and Chemlarova (2005) find that a particular group of countries ('Regime 2' in Table 3 of their paper), that have a moderate income level but a low level of education, have a more pronounced level of CSC compared with countries with a high education ('Regime 1') or countries with both a low income and low education level ('Regime 3'). In this sample it is found that their results hold. CSC is more pronounced in Regime 2 relative to Regime 3, and at the same time it is more pronounced for Regime 2 relative to Regime 1 . It should be noted that these data are not identical to Papageorgiou and Chemlarova (2005). Although the group of Regime 2 is the full sample of countries, data are missing for Hong Kong and Nicaragua from Regime 1, and for the Dominican Republic from Regime 3. Further, the aforementioned paper uses a cross-sectional data set with fewer countries than the panel data set of the current paper. In addition, the data in their paper are from 1988 while the data in the current paper are from 1965 to 1990.

Another point worth noting is that CSC appears to be most prevalent at the lowest threshold. Specifically, in the seven groups of countries considered, five of them show significant evidence of CSC. Recall that DPP were able to find more evidence of CSC when skilled labor was defined at a low threshold. The results here show the extreme case when skilled labor is defined as those who have attained some primary schooling.

Given that the nonparametric approach gives observation-specific parameter estimates, it is possible to further analyze the variation across observations. Appendix B gives the median elasticity for each country along with the corresponding standard error. For countries across the sample, regardless of threshold, there appears to be significant variation in the elasticity of substitution within each measure. Although there is general evidence of CSC across the entire sample, some countries show strong evidence of capital-skill substitutability at each threshold. Again, it is suggested that obtaining a single estimate for an entire panel is not correct for this particular data set. These results show the importance of obtaining observation-specific estimates. 


\section{Comparison by Time Period}

Table 4 presents the median elasticities by year. ${ }^{13}$ The results show general support for CSC. However, the results are often insignificant. As in the previous sub-section, one interesting result is that the strongest results for CSC come when skilled labor is defined as those who have some primary education (the fifth threshold). However, different from both DPP and the previous sub-section is that there is some significant evidence of CSC when skilled labor is defined as those who have attained some college (first threshold). Specifically, in two of the six time periods, there is significant evidence of CSC at the median. This anomaly raises a question that deserves further study.

These results are important for at least two reasons. First, they show some evidence of CSC at the median during the entire sample period. There appears to be no systematic change across time at the median. Second, the strongest evidence of CSC comes when skilled labor is defined by either a high or a low threshold.

\section{Conclusion}

This paper set out to study the CSC hypothesis in a balanced panel of 73 developed and developing countries using nonparametric kernel techniques. This method allowed for three contributions to the literature. (1) The nonparametric approach allowed for the model to be solved using a single-level production function. (2) It did not require a specific functional form to be assumed for the technology, and (3) it allowed for observation-specific estimates of elasticities of substitution. With regard to the first contribution, it was shown that the single-level production function sidestepped the problem of specification choice which arose in the two-level approach. Second, the nonparametric approach made no assumption on the functional form of the technology, nor did it require additional restrictive assumptions such as specifying initial parameters or neutral technological change. Finally, as nonparametric

\footnotetext{
${ }^{13}$ The median refers to the median elasticity of substitution for all countries in a specific time period.
} 
methods give parameter estimates for each observation, it was possible to obtain an elasticity of substitution for each input pair for each observation in the sample.

The inclusion of these techniques on the panel showed some evidence of CSC across the sample. These results appeared to generally hold when examining the quartiles of the elasticities as well as country groups and time medians. Further, the observation-specific estimates allowed for deeper analysis of individual countries, and groups of countries as well as countries across time. The results were shown to be in line with the theories of Goldin and Katz (1998) who suggested that the elasticity of substitution between inputs varies with a country's stage of development and therefore is subject to change over time.

As noted in the introduction, one of the main reasons for studying the CSC hypothesis is to attempt to explain the skilled/unskilled wage differential. Again, if physical capital and skilled labor are found to be more complementary than unskilled labor and physical capital, then an increase in physical capital, ceteris paribus, will increase the demand and thus wages for skilled laborers. Unfortunately, many of the results of this study are insignificant and therefore it is difficult to conclude that CSC is the factor behind the rise in the skilled/unskilled wage differential.

However, it is also premature to rule out CSC as an important factor in cross-country studies. To help answer to this question, it is important to extend this study in several dimensions. First, as was stated in the identification sub-section, imposing constraints from the relevant economic theory on the nonparametric estimators should improve their performance. Also, a longer and wider sample of data may reduce the relatively large standard errors of the nonparametric estimates. That being said, the same could hold true for the estimates in DPP. This may lead to uncovering more cases of significant evidence of CSC.

\section{References}

[1] Abadie, A. (2002). 'Bootstrap tests for distributional treatment effects in instrumental variable models,' Journal of the American Statistical Association, Vol. 97, pp. 284-292. 
[2] Aitchison, J. and Aitken, C. B. B. (1976). 'Multivariate binary discrimination by kernel method,' Biometrika, Vol. 63, pp. 413-420.

[3] Allen, R. G. D. (1938). Mathematical Analysis for Economists, Macmillan, London.

[4] Allen, R. G. D. and Hicks, J. R. (1934). 'A reconsideration of the theory of value, Pt. II,' Economica, Vol. 1, pp. 196-219.

[5] Allon, G., Beenstock, M., Hackman, S., Passy, U. and Shapiro, A. (2007). 'Nonparametric estimation of concave production technologies by entropic measures,' Journal of Applied Econometrics, Vol. 22, pp. 795-816..

[6] Barro, R. J. and Lee, J.-W. (2001). 'International data on educational attainment: Updates and implications,' Oxford Economic Papers, Vol. 53, pp. 541-563.

[7] Bergström, V. and Panas, E. E. (1992). 'How robust is the capital-skill complementarity hypothesis?' Review of Economics and Statistics, Vol. 74, pp. 540-546.

[8] Blackorby, C. and Russell, R. R. (1975). 'The partial elasticity of substitution,' Working Paper, University of California, San Diego.

[9] Blackorby, C. and Russell, R. R. (1981). 'The Morishima elasticity of substitution: Symmetry, constancy, separability, and its relationship to the Hicks and Allen elasticities,' Review of Economic Studies, Vol. 48, pp. 147-158.

[10] Blackorby, C. and Russell, R. R. (1989). 'Will the real elasticity of substitution please stand up? (A comparison of the Allen/Uzawa and Morishima elasticities),' American Economic Review, Vol. 79, pp. 882-888.

[11] Bowman, A. W., Jones, M. C. and Gijbels, I. (1998). 'Testing monotonicity of regression,' Journal of Computational and Graphical Statistics, Vol. 7, pp. 489-500.

[12] Chambers, R. G. (1988). Applied Production Analysis, Cambridge, Cambridge University Press.

[13] Chavas, J.-P. and Cox, T. L. (1988). 'A nonparametric analysis of agricultural technology,' American Journal of Agricultural Economics, Vol. 70, pp. 303-310.

[14] Diamond, P., McFadden, D. and Rodriguez, M. (1978). 'Measurement of the elasticity of factor substitution and bias of technical change,' in M. Fuss and D. McFadden (eds.), Production Economics: A Dual Approach to Theory and Applications, Vol. 2, NorthHolland, Amsterdam, pp. 125-147. 
[15] Duffy, J., Papageorgiou, C. and Perez-Sebastian, F. (2004). 'Capital-skill complementarity? Evidence from a panel of countries,' Review of Economics and Statistics, Vol. 86, pp. 327-344.

[16] Epple, D., Gordon, B. and Sieg, H. (2007). 'A new approach to estimating the production function for housing,' Working Paper, Carnegie Mellon University.

[17] Fallon, P. R. and Layard, P. R. G. (1975). 'Capital-skill complementarity, income distribution, and output accounting,' Journal of Political Economy, Vol. 83, pp. 279-302.

[18] Fan, J. and Gijbels, I. (1996). Local Polynomial Modelling and its Applications, Chapman and Hall, London.

[19] Goldin, C. and Katz, L. F. (1998). 'The origins of technology-skill complementarity,' Quarterly Journal of Economics, Vol. 113, pp. 693-732.

[20] Griliches, Z. (1969). 'Capital-skill complementarity,' Review of Economics and Statistics, Vol. 51, pp. 465-468.

[21] Hall, P. and Huang, L.-S. (2001). 'Nonparametric kernel regression subject to monotonicity constraints,' Annals of Statistics, Vol. 29, pp. 624-647.

[22] Hall, P., Huang, L.-S., Gifford, J. A. and Gijbels, I. (2001). 'Nonparametric estimation of hazard rate under constraint of monotonicity,' Journal of Computational and Graphical Statistics, Vol. 10, pp. 592-614.

[23] Hall, P., Li, Q. and Racine, J. (2007). 'Nonparametric estimation of regression functions in the presence of irrelevant regressors,' Review of Economics and Statistics, Vol. 89, pp. 784-789.

[24] Hall, P. and Van Keilgom, I. (2005). 'Testing for monotone increasing hazard rate,' Annals of Statistics, Vol. 33, pp. 1109-1137.

[25] Henderson, D. J. and Kumbhakar, S. C. (2006). 'Public capital productivity puzzle: A nonparametric approach,' Southern Economic Journal, Vol. 73, pp. 219-232.

[26] Hicks, J. R. (1932). Theory of Wages, Macmillan, London.

[27] Hicks, J. R. (1946). Value and Capital, Clarendon Press, Oxford.

[28] Hoff, A. (2004). 'The linear approximation of the CES function with n input variables,' Marine Resource Economics, Vol. 19, pp. 295-306. 
[29] Hsiao, C., Li, Q. and Racine, J. (2007). 'A consistent model specification test with mixed discrete and continuous data,' Journal of Econometrics, Vol. 140, pp. 802-826.

[30] Hurvich, C. M., Simonoff, J. S. and Tsai, C.-L. (1998). 'Smoothing parameter selection in nonparametric regression using an improved Akaike information criterion,' Journal of the Royal Statistical Society, Series B, Vol. 60, pp. 271-293.

[31] Klump, R. and de La Grandville, O. (2000). 'Economic growth and the elasticity of substitution: Two theorems and some suggestions,' American Economic Review, Vol. 90, pp. 282-291.

[32] Kneip, A. and Simar, L. (1996). 'A general framework for frontier estimation with panel data,' Journal of Productivity Analysis, Vol. 7, pp. 187-212.

[33] Kmenta, J. (1967). 'On estimation of the CES production function,' International Economic Review, Vol. 8, pp. 180-189.

[34] Kumbhakar, S. C., Park, B. U., Simar, L. and Tsionas, E. G. (2007). 'Nonparametric stochastic frontiers: A local maximum likelihood approach,' Journal of Econometrics, Vol. 137, pp. 1-27.

[35] Lewbel, A. and Linton, O. (2007). 'Nonparametric matching and efficient estimators of homothetically separable functions,' Econometrica, Vol. 75, pp. 1209-1227.

[36] Li, Q. and Racine, J. (2004). 'Cross-validated local linear nonparametric regression,' Statistica Sinica, Vol. 14, pp. 485-512.

[37] Li, Q. and Racine, J. (2006). Nonparametric Econometrics: Theory and Practice, Princeton University Press, Princeton.

[38] Maasoumi, E., Racine, J. and Stengos, T. (2007). 'Growth and convergence: A profile of distribution dynamics and mobility,' Journal of Econometrics, Vol. 136, pp. 483-508.

[39] McFadden, D. (1963). 'Further results on C.E.S. production functions,' Review of Economic Studies, Vol. 30, pp. 73-83.

[40] Morishima, M. (1967). 'A few suggestions on the theory of elasticity,' Keizai Hyoron, Vol. 16, pp. 144-150.

[41] Pagan, A. and Ullah, A. (1999). Nonparametric Econometrics, Cambridge University Press, Cambridge. 
[42] Papageorgiou, C. and Chmelarova, V. (2005). 'Nonlinearities in capital-skill complementarity,' Journal of Economic Growth, Vol. 10, pp. 55-86.

[43] Racine, J. and Li, Q. (2004). 'Nonparametric estimation of regression functions with both categorical and continuous data,' Journal of Econometrics, Vol. 119, pp. 99-130.

[44] Rilstone, P. and Ullah, A. (1989). 'Nonparametric estimation of response coefficients,' Communication in Statistics, Theory and Methods, Vol. 18, pp. 2615-2627.

[45] Ruiz-Arranz, M. (2002). 'Wage inequality in the U.S.: Capital-skill complementarity vs. skill-biased technological change,' Working Paper, Harvard University.

[46] Silverman, B. W. (1986). Density Estimation for Statistics and Data Analysis, Chapman and Hall, London.

[47] Temple, J. R. W. (1998). 'Robustness tests of the augmented Solow model,' Journal of Applied Econometrics, Vol. 13, pp. 361-375.

[48] Thompson, P. and Taylor, T. G. (1995). 'The capital-energy substitutability debate: A new look,' Review of Economics and Statistics, Vol. 77, pp. 565-569.

[49] Thursby, J. G. and Lovell, C. A. K. (1978). 'An investigation of the Kmenta approximation to the CES function,' International Economic Review, Vol. 19, pp. 363-377.

[50] Ullah, A. (1988a). 'Nonparametric estimation and hypothesis testing in econometric models,' Empirical Economics, Vol. 13, pp. 223-249.

[51] Ullah, A. (1988b). 'Nonparametric estimation of econometric functionals,' Canadian Journal of Economics, Vol. 21, pp. 625-658.

[52] Uzawa, H. (1962). 'Production functions with constant elasticities of substitution,' Review of Economic Studies, Vol. 29, pp. 291-299.

[53] Vinod, H. D. and Ullah, A. (1988). 'Flexible production estimation by nonparametric kernel estimators,' Advances in Econometrics, Vol. 7, pp. 139-160.

[54] Wang, M. C. and Van Ryzin, J. (1981). 'A class of smooth estimators for discrete estimation,' Biometrika Vol. 68, pp. 301-309. 
TABLE 1

Stochastic dominance tests

\begin{tabular}{lcc}
\hline Null hypothesis & $\mathrm{G}\left(\sigma_{\mathrm{KN}}\right)=\mathrm{F}\left(\sigma_{\mathrm{KS}}\right)$ & $\mathrm{G}\left(\sigma_{\mathrm{KN}}\right) \leq \mathrm{F}\left(\sigma_{\mathrm{KS}}\right)$ \\
\hline Direct elasticity of substitution & & \\
Threshold 1 & 0.000 & 0.000 \\
Threshold 2 & 0.000 & 0.000 \\
Threshold 3 & 0.000 & 0.000 \\
Threshold 4 & 0.000 & 0.954 \\
Threshold 5 & 0.000 & 0.801 \\
& & \\
Allen-Uzawa elasticity of substitution & & \\
Threshold 1 & 0.000 & 0.000 \\
Threshold 2 & 0.000 & 0.598 \\
Threshold 3 & 0.000 & 0.888 \\
Threshold 4 & 0.000 & 0.055 \\
Threshold 5 & 0.000 & 0.000 \\
& & \\
Morishima-Blackorby-Russell elasticity of substitution & \\
Threshold 1 & 0.000 & 0.692 \\
Threshold 2 & 0.000 & 0.957 \\
Threshold 3 & 0.000 & 0.997 \\
Threshold 4 & 0.000 & 0.039 \\
Threshold 5 & 0.000 & 0.015 \\
\hline
\end{tabular}

Notes: Probability values are obtained via bootstrapping. The null hypothesis is rejected if the $p$-value is smaller than some significance level $\alpha,(0<\alpha<1 / 2)$. The first column tests the null hypothesis that the two distributions are equal. The second column tests the null hypothesis that the distribution of elasticity of subsitution estimates between physical capital and unskilled labor dominates the distribution of elasticity of substitution estimates between physical capital and skilled labor (CSC). The thresholds refer to the different definitions of skilled labor. 
TABLE 2

Quartile values for the nonparametric estimates

\begin{tabular}{cccc}
\hline & $\mathrm{Q} 1$ & $\mathrm{Q} 2$ & $\mathrm{Q} 3$ \\
\hline$\sigma_{\mathrm{KS} 1}$ & -8.311 & -0.440 & 3.436 \\
& 22.319 & 0.680 & 0.763 \\
$\sigma_{\mathrm{KS} 2}$ & $-19.713{ }^{*}$ & -0.381 & 2.772 \\
& 4.515 & 0.955 & 3.695 \\
$\sigma_{\mathrm{KS} 3}$ & -5.695 & 0.067 & 3.685 \\
& 4.948 & 0.686 & 5.157 \\
$\sigma_{\mathrm{KS} 4}$ & -0.873 & -0.050 & 0.651 \\
& 0.853 & 0.841 & 1.048 \\
$\sigma_{\mathrm{KS} 5}$ & -1.281 & 0.010 & 2.233 \\
& 0.665 & 0.689 & 0.370 \\
& & & \\
$\sigma_{\mathrm{KN} 1}$ & 0.482 & 1.950 & 4.728 \\
& 0.444 & 0.513 & 3.693 \\
$\sigma_{\mathrm{KN} 2}$ & 0.256 & 2.553 & 7.379 \\
& 3.034 & 8.241 & 1.521 \\
$\sigma_{\mathrm{KN} 3}$ & -1.588 & 0.917 & 7.933 \\
& 2.996 & 2.087 & 3.894 \\
$\sigma_{\mathrm{KN} 4}$ & -2.092 & 1.105 & 4.892 \\
& 1.649 & 2.806 & 1.453 \\
$\sigma_{\mathrm{KN} 5}$ & -0.344 & 3.152 & 26.004 \\
& 0.565 & 1.963 & 14.650 \\
\hline
\end{tabular}

Notes: In the regression function used to estimate each of these Morishima-Blackorby-Russell elasticities, the dependent and independent variables are in levels. Region and time effects are also included. Q1, Q2 and Q3 refer to the first, second, and third quartile, respectively. S1-S5 and N1-N5 refer to the different definitions for skilled and unskilled labor, respectively. AICc used for bandwidth selection. Standard errors are listed in italics beneath each estimate. The symbol * $(+)$ corresponds to where the quantile estimates show significant evidence of CSC at the 5\% (10\%) level. 
TABLE 3

Median elasticity of substitution across different groups of countries

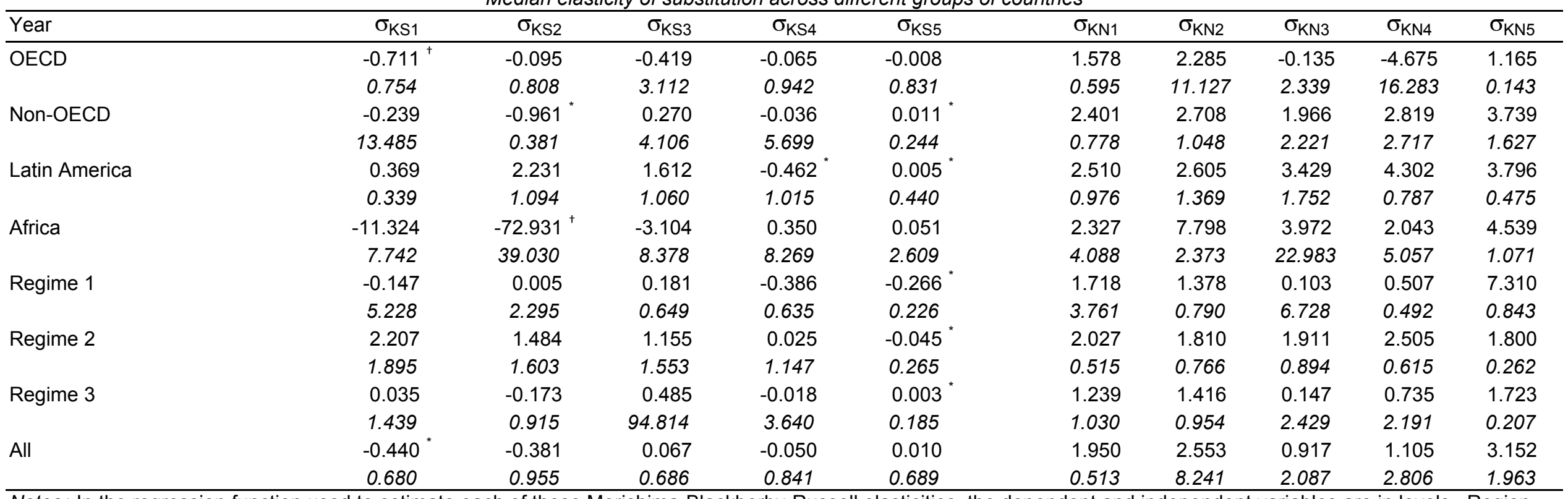

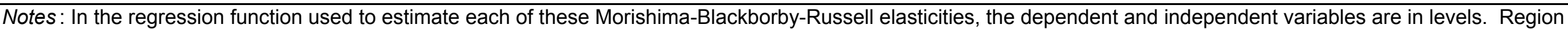

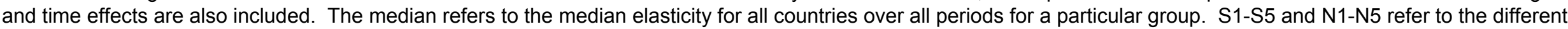

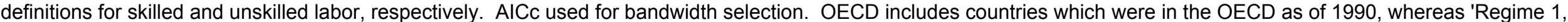

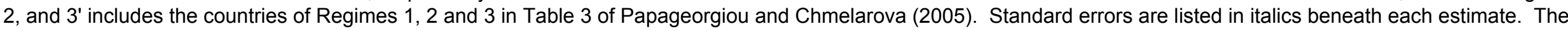
symbol $^{*}(\dagger)$ corresponds to where the median estimates exhibit significant evidence of CSC at the 5\% (10\%) level. 
TABLE 4

Median elasticity of substitution across countries for each time period

\begin{tabular}{|c|c|c|c|c|c|c|c|c|c|c|}
\hline Year & $\sigma_{\mathrm{KS} 1}$ & $\sigma_{\mathrm{KS} 2}$ & $\sigma_{\mathrm{KS} 3}$ & $\sigma_{\mathrm{KS} 4}$ & $\sigma_{\mathrm{KS} 5}$ & $\sigma_{\mathrm{KN} 1}$ & $\sigma_{\mathrm{KN} 2}$ & $\sigma_{\mathrm{KN} 3}$ & $\sigma_{\mathrm{KN} 4}$ & $\sigma_{\mathrm{KN} 5}$ \\
\hline \multirow[t]{2}{*}{1965} & -0.467 & 0.194 & 1.287 & $-0.099^{\dagger}$ & 0.006 & 2.329 & 2.495 & 2.653 & 2.259 & 3.241 \\
\hline & 0.761 & 1.575 & 2.785 & 0.300 & 0.440 & 4.088 & 0.837 & 3.931 & 1.043 & 2.413 \\
\hline \multirow[t]{2}{*}{1970} & -0.673 & 0.393 & -3.922 & -0.085 & $-0.305^{*}$ & 2.264 & 2.956 & 0.062 & 1.240 & 3.411 \\
\hline & 7.202 & 3.090 & 3.305 & 1.692 & 0.328 & 0.694 & 0.797 & 2.864 & 0.745 & 0.359 \\
\hline \multirow[t]{2}{*}{1975} & -1.562 * & -0.915 & -0.368 & -0.053 & $-0.327^{*}$ & 1.962 & 2.568 & 0.059 & 1.269 & 2.916 \\
\hline & 0.541 & 2.071 & 1.598 & 0.441 & 0.328 & 0.559 & 0.577 & 1.781 & 0.616 & 0.570 \\
\hline 1980 & 2.625 & 4.633 & 0.428 & 0.151 & 0.109 & 0.769 & 12.465 & 0.772 & 0.764 & 0.359 \\
\hline \multirow[t]{2}{*}{1985} & $-1.191^{\dagger}$ & -2.246 & -1.937 & 0.015 & -0.037 & 1.008 & 2.786 & 0.492 & 0.918 & 1.309 \\
\hline & 0.769 & 2.774 & 35.846 & 1.777 & 0.048 & 0.413 & 0.751 & 1.612 & 2.035 & 3.921 \\
\hline \multirow[t]{2}{*}{1990} & 1.956 & $-0.988^{*}$ & 2.716 & -0.453 & 1.197 & 2.090 & 0.990 & 2.041 & 0.487 & 11.911 \\
\hline & 15.370 & 0.381 & 1.915 & 2.316 & 0.490 & 0.657 & 0.497 & 1.727 & 0.274 & 23.328 \\
\hline \multirow[t]{2}{*}{ All } & $-0.440^{*}$ & -0.381 & 0.067 & -0.050 & 0.010 & 1.950 & 2.553 & 0.917 & 1.105 & 3.152 \\
\hline & 0.680 & 0.955 & 0.686 & 0.841 & 0.689 & 0.513 & 8.241 & 2.087 & 2.806 & 1.963 \\
\hline
\end{tabular}

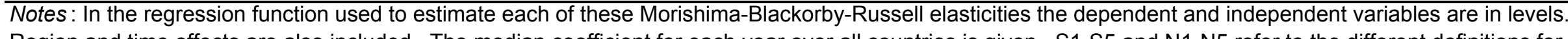

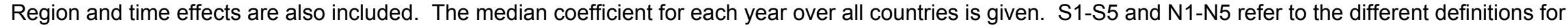
skilled and unskilled labor, respectively. AICc used for bandwidth selection. Standard errors are listed in italics beneath each estimate. The symbol * + ) corresponds to where the median estimates exhibit significant evidence of CSC at the 5\% (10\%) level. 